\title{
Experimental investigations of acoustic field in sea shelf zone
}

\author{
Vasiliy Chernenko ${ }^{1 *}$, Chen Ven'tszyan' ${ }^{2}$, Viktor Petrosyants ${ }^{3}$, Ivan Garasev ${ }^{1}$, Vladimir Grishchenko ${ }^{1}$. \\ ${ }^{1}$ FEFU, Engineering school, Department of instrumentation, Russia \\ ${ }^{2}$ College of Underwater Acoustic Engineering, China \\ ${ }^{3}$ FEFU, Engineering school, Department of electronics and communications, Russia
}

\begin{abstract}
Developed experimental facility allows one to generate acoustic pressure within the intervals from $10^{5}$ to $10^{6} \mathrm{~Pa}$ with an affective system of matching layers of bottom, water and ice. Theoretical and experimental investigations showed the possibility of information transfer in a shallow sea under an ice layer. Experimental acoustic system allows one to make measurements in a wide frequency range from 40 to $1100 \mathrm{~Hz}$. The conducted investigation can be used to develop effective remote communication and to model earthquake acoustic precursor measurements.
\end{abstract}

\section{Introduction}

Seismic activity in arctic latitudes under an ice layer is accompanied by acoustic deformation of ice cover [1]. Acoustic elastic waves occur in an ice layer in the rage from units to tens of $\mathrm{kHz}[2,3,4,5]$. In order to record earthquake sources deep under the water and far away from an ice edge, we need to develop mathematical models for the processes of elastic acoustic wave propagation at the boundary of water and ice. The paper $[6,7,8]$ presents the investigation results for elastic acoustic wave propagation along an ice edge by a powerful pulse air generator. Such a generator [9] allows us to generate powerful pulses of elastic waves at the frequencies of $30-70 \mathrm{~Hz}$ with the repetition period up to $5 \mathrm{~Hz}$. It is possible to obtain stronger pulses at higher frequencies by an electrohydraulic shock [10]. The aim of the paper is the development of powerful hydroacoustic radiators based on pneumatic and elecrohydraulic effect to investigate the interaction of elastic waves with ice layer in real conditions.

\footnotetext{
*Corresponding author: ga i uzt@mail.ru
} 


\section{Methods and materials}

The main aim of the experiment is the information transfer in a shallow sea under an ice layer.

The main tasks of the experiment were to obtain and to compare signals from different experimental facilities under an ice layer.

Measurement of field characteristics in a far-field zone is of great importance.

To ensure this requirement, the following conditions should be fulfilled:

1) quite a long distance from a radiator to a receiver to satisfy the criteria of a free field;

2) known values of some parameters, for example, distance, magnetic and dielectric permeability and electromagnetic wave frequency. It is difficult to realize the requirements in practice, thus, one should always take into account introduced assumptions;

In order to carry out the experiments, we developed experimental facilities, they are: a low-frequency pneumatic radiator of powerful acoustic signals and an electro hydraulic generator.

Fig. 1 and 2 show the physical configuration of the pneumatic radiator.

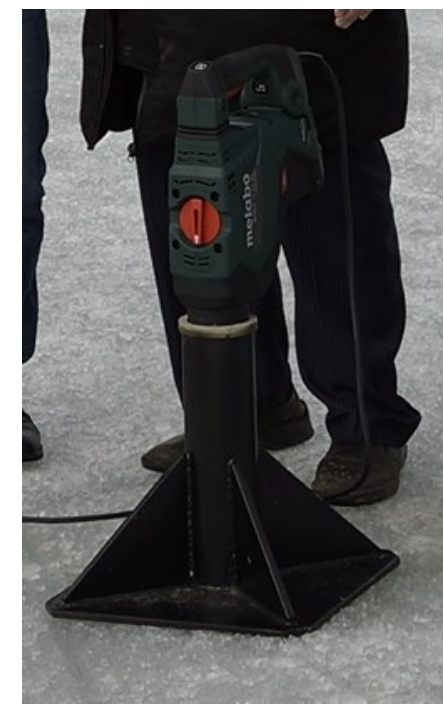

a)

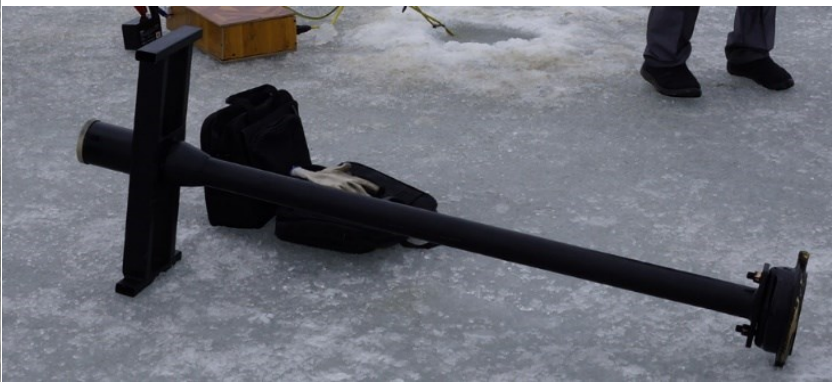

b)

Fig. 1. a) Over-ice part of the radiator. b) under-ice part of the radiator.

Main characteristics of the radiator:

- Work is $20 \mathrm{~J}$.

- Frequency range is from $40 \mathrm{~Hz}$ to $1000 \mathrm{~Hz}$. 


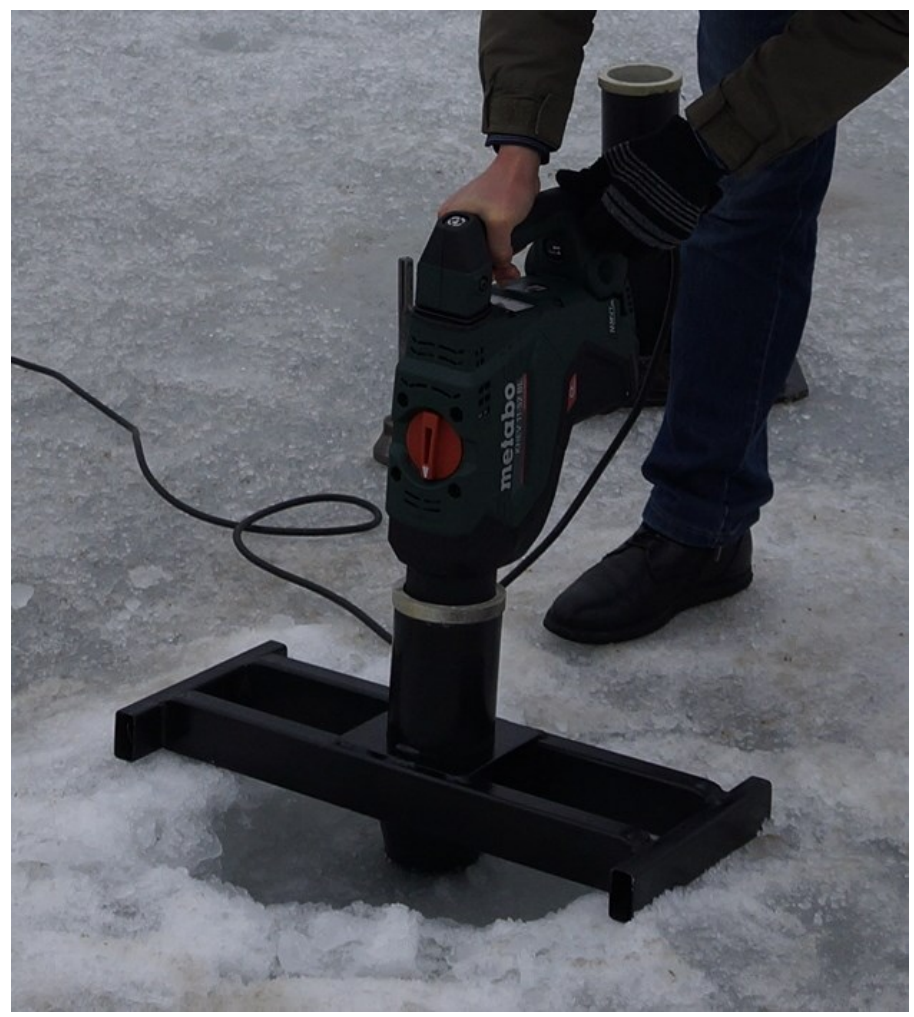

Fig. 2 Application of the radiator.

Electro hydraulic generator is illustrated in Fig. 3.

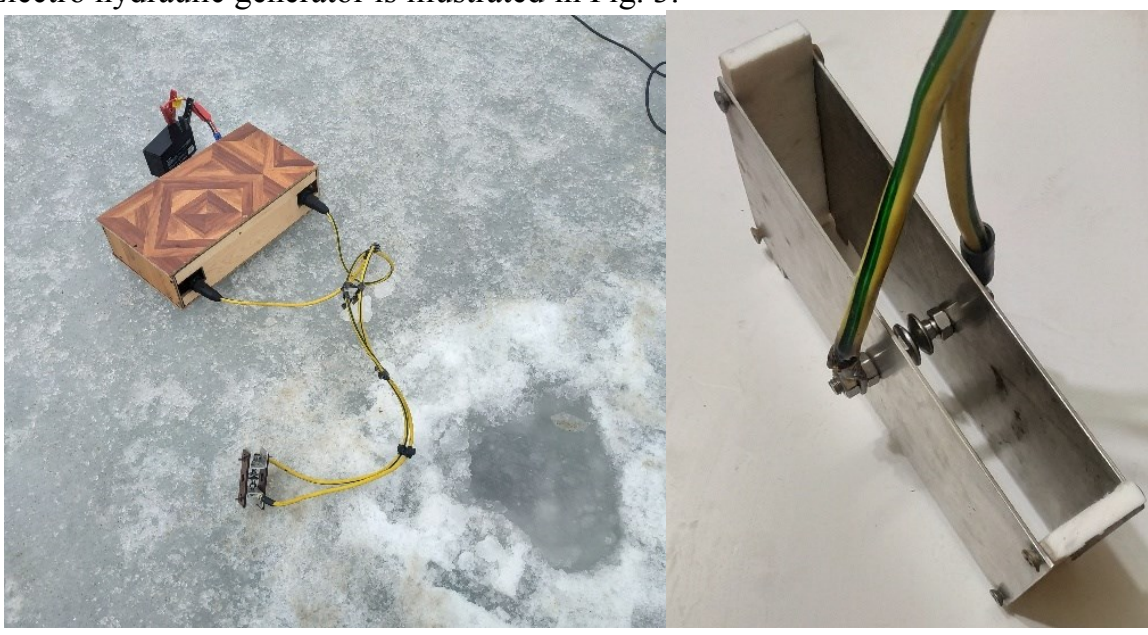

a)

b)

Fig. 3. Electro hydraulic generator: a) physical configuration of the unit; b) electric hydraulic radiator

Fig. 4 shows a functional scheme of the electro hydraulic generator operating from an electric accumulator.

The facility for acoustic elastic wave generation is operating as follows. Direct voltage of $24 \mathrm{~V}$ is applied from accumulator though the switch 2 to the control system 3 and 
voltage converter 4 . The control system is on a microcontroller and has a Bluetooth module to connect to a PC. Bluetooth connection allows us to assign pulse relative duration at the electric hydraulic radiator 9 output in the remote and online modes. Pulse energy depends on the charge voltage of the storage capacitor $\left(C_{H}\right) 7$. Charge voltage of $C_{H}$ is defined by the change of gaps in the high-voltage dischargers 8 . Repetition frequency of a pulse group is limited by the time of complete discharging of $C_{H}$. The time of complete discharging of $C_{H}$ is determined by the resonance frequency and the quality of the discharge resistor circuit.

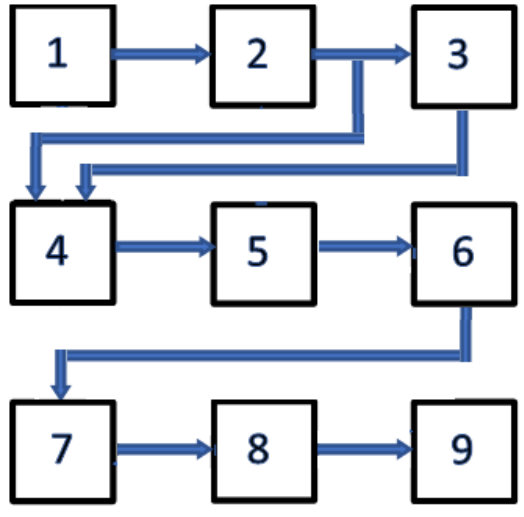

a)

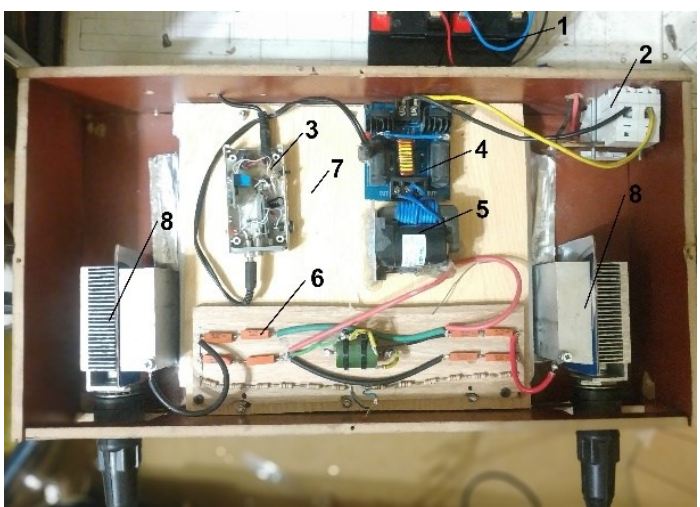

b)

Fig. 4. Functional scheme of acoustic elastic wave generation: a) functional scheme; b) physical configuration of the generator. 1 - accumulator; 2 - switch; 3 - control system; 4 - voltage converter; 5 - high-voltage transformer; 6 - rectifying element; 7 - storage capacitor; 8 - high-voltage dischargers; 9 - electric hydraulic radiator.

\section{Information and measuring system}

To check experimentally the operational performance of the pulse electro hydraulic generator of acoustic elastic waves, we constructed an information and measuring system (IMS), the functional scheme of which is illustrated in Fig. 5.

The IMS is operating as follows. The EHG parameters, defining the elastic wave pulse duration, are uploaded by the help of a PC and serial input-output interface via Bluetooth connection. The electric hydraulic radiator is submerged at an appropriate depth though a hole made in the ice. The hydrophone is submerged through another hole at a defined distance from the EHR. A gydroacoustic pulse is received by the hydrophone $\mathrm{HPh}$, is amplified by hydrophone amplifier HA, is converted into a digital code via the ADC and enters PC for data processing and display. 

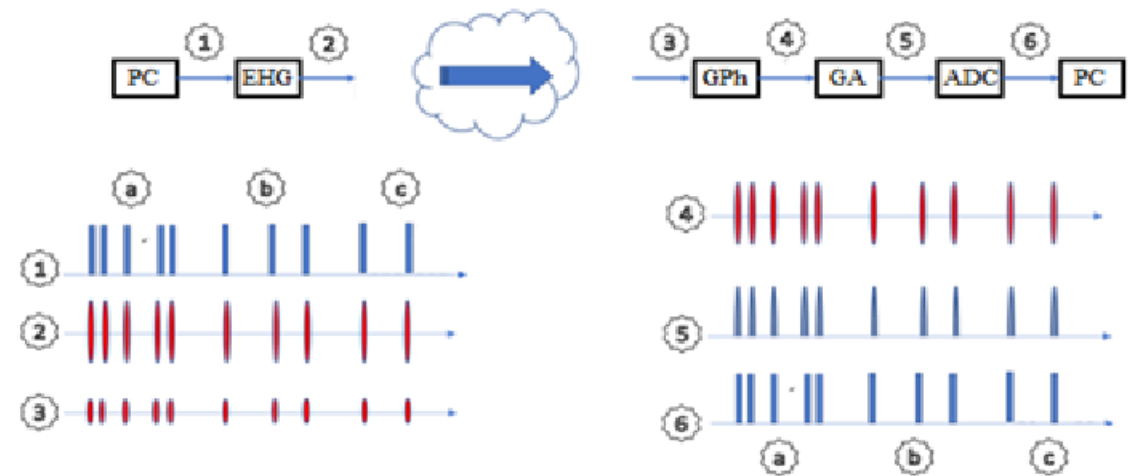

Fig.5. Functional scheme of the information and measuring system: PC - personal computer; EHG electro hydraulic generator; $\mathrm{HPh}$ - hydrophone; GA - hydrophone amplifier; ADC - analogue-todigital converter.

\section{Results}

The investigations were carried out in winter time under the following conditions: air temperature was minus $8^{\circ} \mathrm{C}$; wind velocity was not more than $5 \mathrm{~m} / \mathrm{s}$; ice layer was $0.3-0.4$ $\mathrm{m}$; water temperature was $1^{\circ} \mathrm{C}$; radiator submerged depth was $6 \mathrm{~m}$; that for the hydrophone was $1 \mathrm{~m}$; distance between the radiator and the hydrophone was $40 \mathrm{~m}$; depth at the experimental area was $8 \mathrm{~m}$; bottom was formed with sand, stones and water-inhabiting plants.

A low-frequency pneumatic generator of powerful acoustic signals (Fig. 1) and an electro hydraulic generator (Fig. 3) were used in the experiment.

Signals were received by an omnidirectional hydrophone. The hydrophone is a piezoceramic spherical Ø $50 \mathrm{~mm}$ one. Its sensitivity is within the range of $20-2000 \mathrm{~Hz}-$ $180 \mu \mathrm{V} / \mathrm{Pa} \pm 20 \%$. The hydrophone capacity with the cable of $6 \mathrm{~m}$ is $34 \mathrm{nF} \pm 20 \%$.

As a hydrophone amplifier we used a voltage one with the gain factor $\mathrm{Gf}=200$, input resistance $\mathrm{RBX}_{\mathrm{B}}=10 \mathrm{~m} \Omega$ and the pass band $\Delta \mathrm{f}=2-4000 \mathrm{~Hz}$ at the level of $-3 \mathrm{~dB}$.

A multifunctional unit myDAQ (National Instruments) connected to a laptop was used as a recording unit for the signals received by the hydrophone. The signal sampling frequency was $10 \mathrm{kHz}$, ADC capacity was 16 binary digits. In order to protect it from air temperature change effect, the hydrophone amplifier, multifunctional unit myDAQ and the laptop were placed inside a building, where the temperature was within $15 \pm 2^{\circ} \mathrm{C}$. Specialized software in LabView environment was used for signal recording and further analysis.

Fig. 6 illustrate signal oscillograms recorded at the distance of $40 \mathrm{~m}$ from the radiator (electric hydraulic generator). 


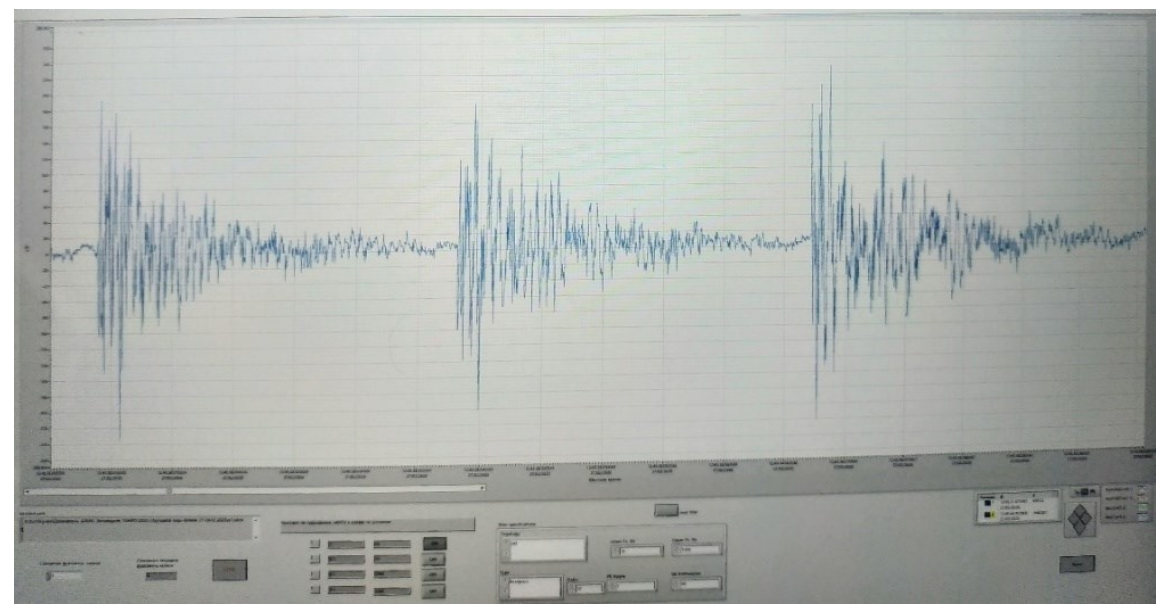

Fig. 6. Oscillogram of signal periodic sequence recorded at the distance of $40 \mathrm{~m}$ from the radiator within the interval from 12:45:38.00 to 12:45:38.09 of local time. Horizontal axis is local time, vertical axis is acoustic pressure in $\mathrm{Pa}$.

Fig. 7 illustrates an oscillogram for the signals recorded at the distance of $100 \mathrm{~m}$ from the radiator (pneumatic radiator).

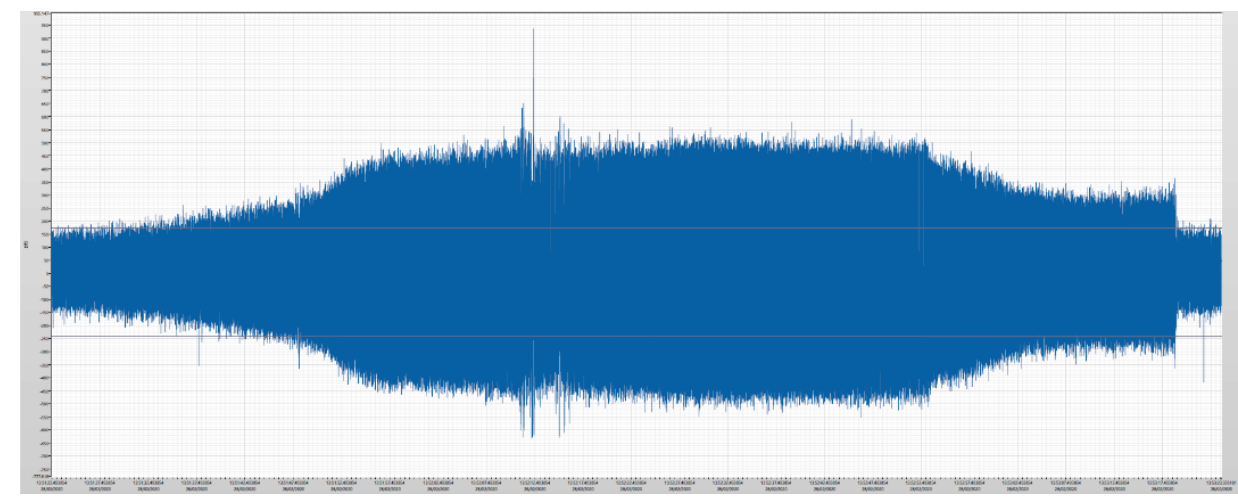

Fig 7. Oscillogram of signal periodic sequence recorded at the distance of $100 \mathrm{~m}$ from the radiator within the interval from 13:51:22.5 to 13:53:23.6 of local time. Horizontal axis is local time, vertical axis is acoustic pressure in $\mathrm{Pa}$.

Fig. 6 shows a signal received from the EHG located at the distance of $40 \mathrm{~m}$. The signal represents a sequence of relaxation oscillation pulses with shock excitation and frequency filling. The period of pulse group repetition in this experiment is $\mathrm{T}=30 \mathrm{~ms}$. The control scheme of EHG allows us to obtain shock acoustic waves with the repetition frequency up to $\mathrm{F}=33 \mathrm{~Hz}$ starting with single pulses.

Fig. 7 illustrates a signal received from a pneumatic radiator. The signal represents a sequence of strong elastic pulse oscillations with shock excitation and frequency filling. Pulse frequency is up to $1000 \mathrm{~Hz}$. In the course of the experiment shock acoustic waves with the repetition frequency from $40 \mathrm{~Hz}$ were obtained.

\section{Discussion}


Comparison of the parameters of EHG hydroacoustic signals $(\mathrm{F}=0-33 \mathrm{~Hz}, \mathrm{f}=3 \mathrm{kHz})$ and of pneumatic radiator $(\mathrm{F}=0-3 \mathrm{~Hz}, \mathrm{f}=50 \mathrm{~Hz})$ [7] with the parameters of acoustic waves from real earthquakes $(\mathrm{F}=0.1-0.5 \mathrm{~Hz}, \mathrm{f}=0-22 \mathrm{kHz})$ allows us to make a conclusion on the possibility of modeling of the suggested experimental facilities to investigate elastic waves in water environments covered with ice in the range up to several $\mathrm{kHz}$.

\section{Conclusions}

Experimental investigations of the pneumatic radiator and the electro hydraulic generator showed a principle possibility to apply them for physical modeling of propagation of hydroacoustic elastic waves with shock excitation and frequency filling in water environments covered with ice as well as for data transmission under conditions of ice cover.

\section{References}

1. Yu. Marapulets, B. Shevtsov, Dalnauka, 125 (2012)

2. I.Dolgikh, A. Kuptsov, I. Larionov, Yu. Marapulets, V. Shvets, B. Shevtsov, O. Shirokov, V. Chupin, S. Yakovenko, DAN, 413, 1 (2007)

3. A. Kuptsov, I. Larionov, B. Shevtsov, Volcanology and seismology, 4, 1 (2005)

4. A. Kuptsov, Physics of the Earth, 10, 59-65 (2005)

5. V. Gordienko, T. Gordienko, A. Kuptsov, DAN, 407, 5 (2006)

6. V. Korochentsev, N. Zorchenko, A. Potapenko, ICIEAM, 1432-1435 (2017)

7. V. Korochentsev, I. Tszinvey, A. Viland, T. Lobova, N. Soshina, E3S Web of Conferences 127, 02006 (2019).

8. Korochentsev V.I. Volnovye zadachi teorii napravlennykh i fokusiruyushchikh antenn [Wave problems in the theory of directed and focused antennas]. Moscow, Dal'nauka, Vladivostok, 1998, 192 p. (in Russian)

9. Chen W., Chernenko V., Petrosyants V., Grishchenko V. E3S WEB of conferences. 2019г. с 02006.

10. Shen-Min Liang, Kiet-Houng Chow, Ioannis Manousaka, Yong-Ren Pu, Chien-Chen Chang. Biomed. Eng. Appl. Basis Commun. 2006.18:24-29. 